\title{
Минеральные ассоциации низкотемпературных жил и зон окисления проявления Кондобережская (Онежская структура, Карелия)
}

\author{
Лавров О.Б., Кулешевич Л.В. \\ Институт геологии КарНЦ РАН, Петрозаводск, petrlavrov@list.ru; kuleshev@krc.karelia.ru
}

\begin{abstract}
Аннотация. Район дер. Кондобережская в Онежской палеопротерозойской структуре известен тем, что здесь в результате поисковых работ, проводимых ПО «Северкварцсамоцветы» в 80-е годы прошлого века, было открыто уникальное для докембрия проявление пестроцветных яшм и карнеол-агатов. Проявление приурочено к шунгитоносным породам заонежской свиты людиковия. Карнеол-агаты представлены концентрически зональными оранжево-красными обособлениями размером до 30 см. При обследовании западного участка проявления выяснилась, что карнеол-агатовая минерализация приурочена к С3 зоне окварцевания по шунгитоносным породам. С ней связаны несколько (сульфидно-кварцевых) минеральных ассоциаций: 1 - низкотемпературная гидротермальная полиметаллическая, представленная селенидно-полисульфидным парагенезисом; 2 - гидротермальная окисная, представленная гематитом, гетитом, карнеол-агатом, аметистом, горным хрусталем, кальцитом и баритом. Заключительный этап минералообразования проявился в формировании вторичных минералов, типоморфных для зон окисления: самородных селена и серы и других более редких минералов. Самородный селен встречается в виде продуктов окисления клаусталита $\mathrm{PbSe}$.

Ключевые слова: самородный селен, сульфиды, гематит, гетит, карнеол, редкие минералы, зона окисления, палеопротерозой, Онежская структура, Карелия.
\end{abstract}

\section{Mineral associations of low-temperature veins and oxidized zones of the Kondoberezhskaja occurrence (Onezhskaja structure, Karelia)}

Lavrov O.B., Kuleshevich L.V.

Institute of Geology, Karelian Research Centre, RAS (KarRC RAS), Petrozavodsk, petrlavrov@list.ru; kuleshev@krc.karelia.ru

\begin{abstract}
The Kondoberezhskaya village area, located in the Paleoproterozoic Onega Structure, is famous for a unique Precambrian multi-coloured jasper and carneol-agate occurrence discovered as a result of prospecting conducted by Severquartzsamotsvety Company in the 1980s. The occurrence is confined to shungite-bearing rocks occurring as part of the Ludicovian Trans-Onega suite. Carneol-agates occur as concentrically zonal orangered aggregates up to $30 \mathrm{~cm}$ in size. The study of the West Prospect has shown that carneol-agate mineralization is confined to a NW-trending silicification zone after shungite-bearing rocks. There are several sulphide-quartz mineral associations associated with it: 1 - a low-temperature base-metal association consisting of selenide-polysulphide paragenesis; 2 - a hydrothermal oxide association composed of hematite, goethite, carneol-agate, amethyst, rock crystal, calcite and barite. Secondary minerals, such as native selenium, sulphur and other more scarce minerals typomorphic for oxidation zones, were derived at the final stage of mineral formation. Native selenium occurs as oxidation products of clausthalite, $\mathrm{PbSe}$.
\end{abstract}

Keywords: native selenium, sulphides, hematite, goethite, carneol, rare minerals, oxidation zone, Paleoproterozoic, Onega Structure, Karelia.

\section{Введение}

Район дер. Кондобережская в Онежской палеопротерозойской структуре известен тем, что здесь в результате поисковых работ, проводимых ПО «Северкварцсамоцветы» в 80-е годы прошлого века, было открыто уникальное для докембрия проявление пестроцветных яшм и карнеол-агатов. Проявление приурочено к шунгитоносным породам заонежской свиты людиковия. Карнеол-агаты представлены концентрически зональными оранжево-красными обособлениями размером до 30 см. При обследовании западного участка проявления выяснилась, что карнеол-агатовая минерализация приурочена к С3 зоне окварцевания по шунгитоносным породам. К югу от Великой губы с 18 века известны проявления аметиста (о. Волкостров) и барита (о. Южный Олений). Авторами изучался 
материал кварцевых жил, секреций и обломочного материала (минералы группы кварца, сульфиды, селениды, оксиды) с проявления Кондобережская (первичная и вторичная рудная минерализация).

\section{Методы исследования}

Минеральный состав рудных и нерудных ассоциаций жил изучался с использованием электронного сканирующего микроскопа VEGA II LSH (Tescan) с энергодисперсионным микроанализатором INCA Energy-350 в аналитическом центре ИГ КарНЦ РАН (г. Петрозаводск). Фотографии сделаны с образцов и аншлифов из коллекций музея геологии докембрия (ИГ КарНЦ РАН).

\section{Результаты исследования}

Рудная минерализация кварцевых жил. В районе поселка Великая Губа (участок Кондобережская) вмещающие толщи представлены породами людиковийского надгоризонта. Район является юго-восточным флангом Святухинско-Космозерской зоны складчато-разрывных деформаций (Онежская..., 2011) и характеризуется различными типами полезных ископаемых (рис. 1): уранванадиевыми рудами (месторождение Космозеро, проявления Южно-Космозерское, Великая Губа, Яндомозеро), Великогубским шунгитовым и полиметаллическим проявлениями (Минерально..., 2006), а также находками карнеол-агатов (Кондобережская) (Гутцайт, 1987).

В геологическом строении района Великой Губы принимают участие шунгитоносные толщи палеопротерозойского возраста, прорванные силлами габбродолеритов (PR $1 \mathrm{~d})$. Вмещающие породы секутся кварцевыми жилами, образующими штокверки. Вдоль побережья залива накопился постледниковый обломочный материал недальнего переноса, представленный обломками местных пород и жил.

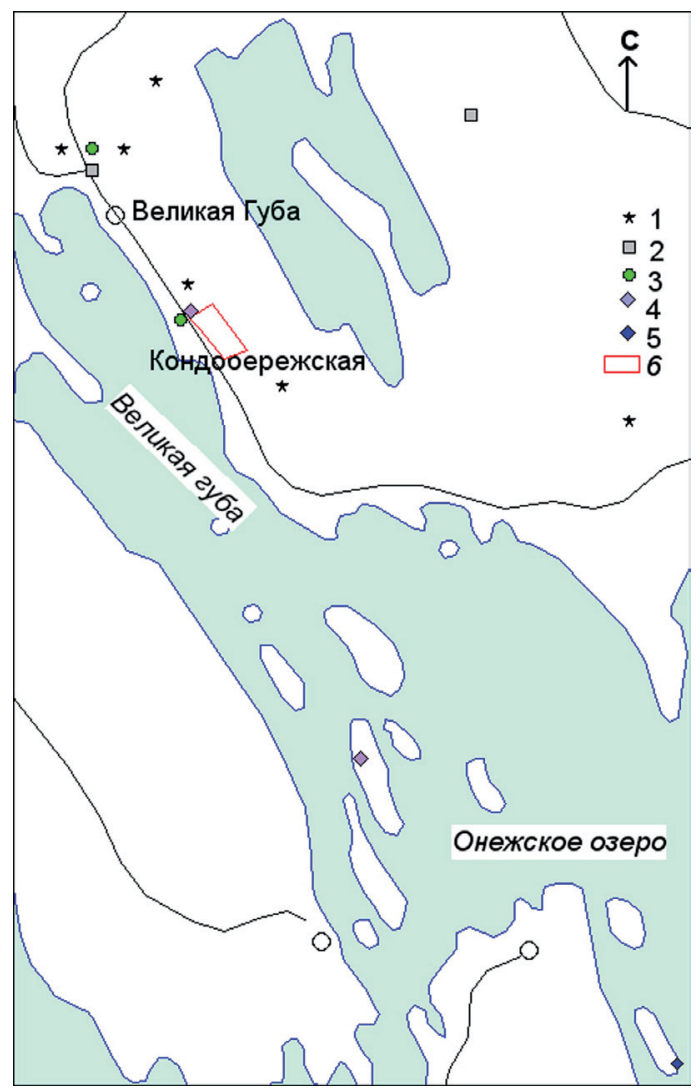

Рис. 1. Схема размещения проявлений в юго-восточной части Святухинско-Космозерской СРД (район пос. Великая Губа).

1 - U-V; 2 - шунгитовые; 3 - сульфидные полиметаллические; 4 - кварц-самоцветное сырье; 5 - барит; 6 - участок Кодобережская.

Fig. 1. Distribution scheme of occurrences in the southeastern Svyatuknino-Kosmozero SRD (Velikaya Guba area). 

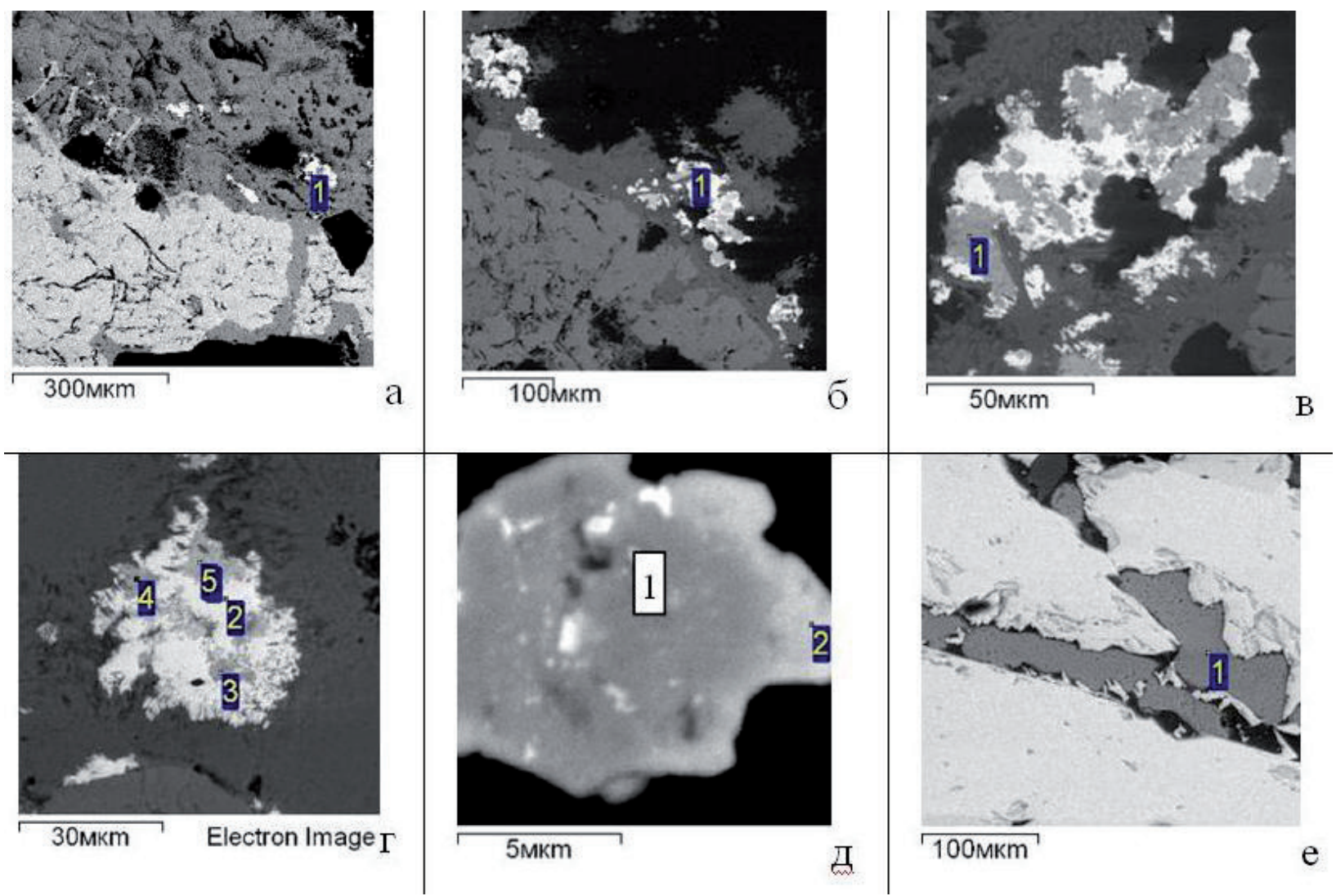

Рис. 2. Клаусталит, самородные селен, сера и более редкие селениды (проявление Кондобережская). A - пирит замещается гематитом, клаусталит (1); б - клаусталит в гематите, замещающем пирит; в-г - клаусталит (белый) частично замещен селеном (светло-серый); д - тиррелит (1) $(\mathrm{Cu}, \mathrm{Co}, \mathrm{Ni})_{3} \mathrm{Se}_{4}$ с каймой кадмоселита $\mathrm{CdSe}$ и реликтами клаусталита (белый); е - сфалерит (белый), по трещинкам выделяется сера (1).

Fig. 2. Clausthalite, native selenium, sulfur and more scarce selenides (Kondoberezhskaya occurrence).

Жилы выполнены кварцем, реже кальцитом и баритом. Они содержат сульфиды и селениды. Среди рудной минерализации жил можно выделить несколько типов: 1 - низкотемпературную гидротермальную полиметаллическую, представленную кварцем, пиритом, сфалеритом, халькопиритом, марказитом, галенитом, клаусталитом и более редкими селенидами; 2 - окисленную гидротермальную ассоциацию, представленную гематитом, гетитом, карнеол-агатом, баритом, кальцитом. В зоне окисления образуются различные окисленные минералы. Среди вторичных минералов зоны окисления (3 тип) установлены самородный селен, сера, пластинчатый ковеллин, англезит, ярозит, коркит, лимонитовые смеси (гематит-гетитовые).

1 mип минерализации. В ассоциации с кварцем более всего распространен пирит, он содержит примесь Со 1-4 \%. Пирит дробится и замещается лимонитом (гематитом и гетитом). Халькопирит встречается реже. Он образуется после пирита и при окислении замещается пластинчатым ковеллином. Сфалерит представлен двумя генерациями, которые отличаются по составу примесей: 1) содержит Fe в количестве до 6-8.4 \%, 2) содержит $\mathrm{Cd}$ до 4 \%, но без Fe. Галенит тонкозернистый, ассоциирует с клаусталитом сечет пирит, содержит до 1-3 \% Se. При окислении галенит замещается англезитом.

Селениды представлены преимущественно клаусталитом PbSe (рис. 2). При замещении пирита гематитом, клаусталит начинает постепенно замещаться самородным селеном. При этом в новообразованном минерале-селене сохраняются мельчайшие реликты клаусталита, они же встречаются и в сплошых гематит-гетитовых агрегатах.

Среди селенидов выделяются весьма редкие срастания тиррелита (Cu,Co,Ni) ${ }_{3} \mathrm{Se}_{4}(\mathrm{Se} 71.09-72.62 \%$, $\mathrm{Cu}$ 11.86-9.55 \%, Fe 1.86-1.91 \%; Co 7.58-8.02 \%, Ni 5.74-6.02 \%, Cd до 3.75 \%), и кадмоселита CdSe 


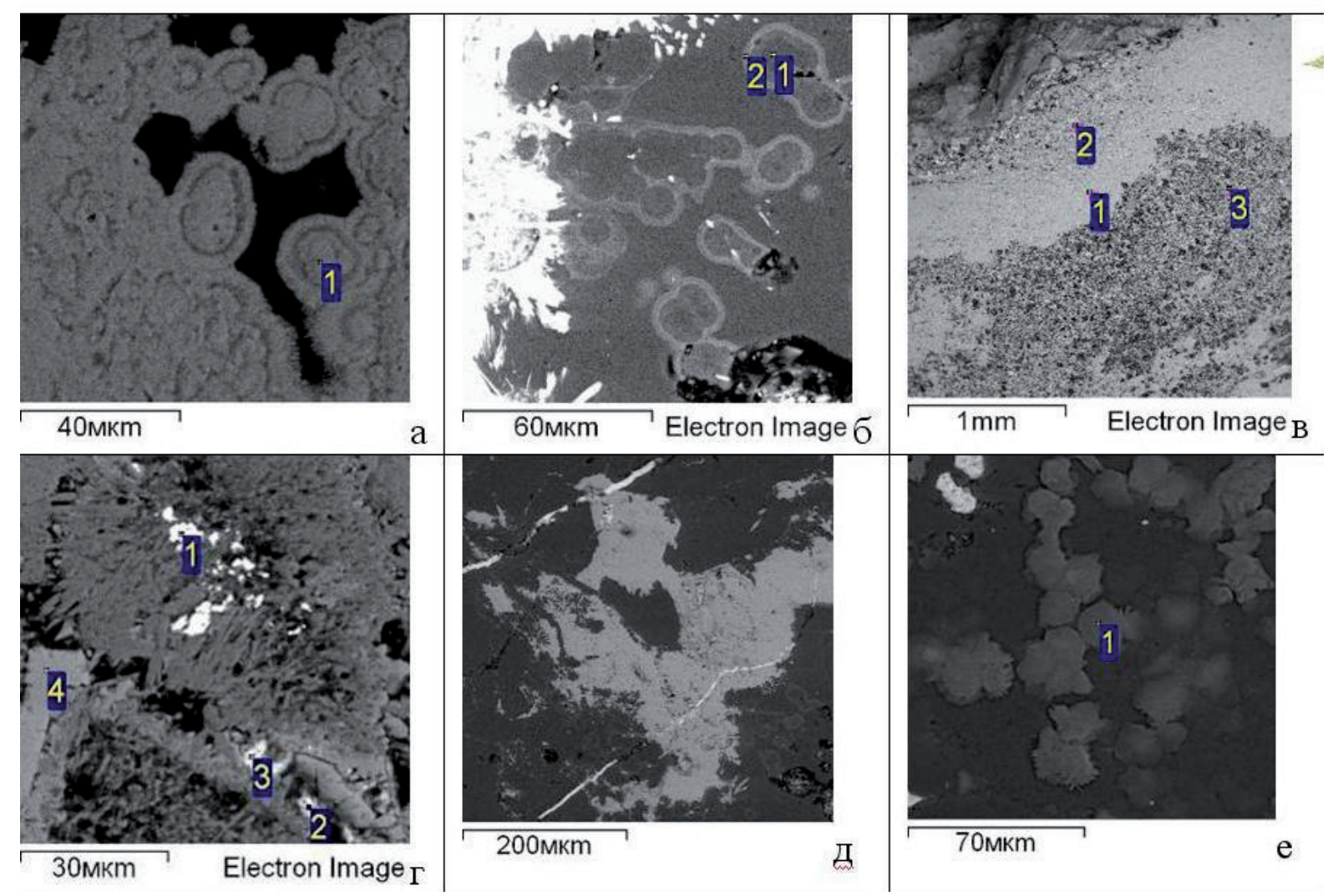

Рис. 3. Минералы зоны окисления (проявление Кондобережская).

А - срастание гематит-гетит (почки), б - гематит (белый) в срастании с зональным карнеолом, в - зоны в карнеол-агате, г - игольчтый гетит с включениями клаусталита с селеном (1-3), пирит (4), д- гематит (серый), сечется коркитом (белые тонкие прожилки), е - ярозит (1) в срастании с тонкодисперсным кварцем (черный), слева (белый) сфалерит.

Fig. 3. Oxidation zone minerals (Kondoberezhskaja occurrence).
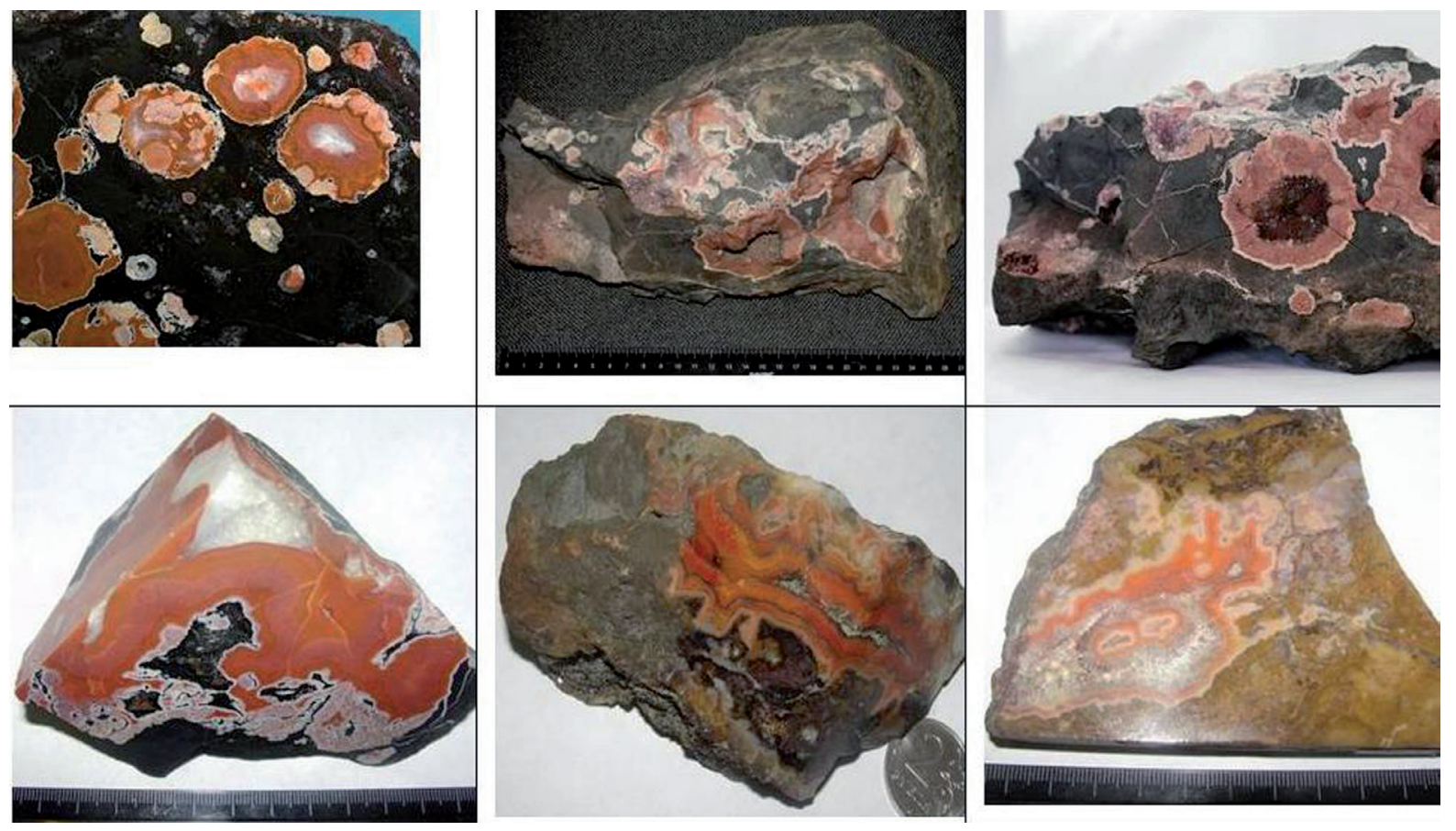

Рис. 4. Карнеол-агаты (проявление Кондобережская).

Fig. 4. Carneol-agates (Kondoberezhskaja occurrence). 
( $\mathrm{Se} 41.05 \%$, Cd $58.95 \%$ ), развитого в кайме (рис. 2 д). В них также иногда встречаются реликты клаусталита. Эти редкие находки были сделаны О.Б. Лавровым.

Низкотемпературная окисная гидротермальная ассоциация 2 типа представлена гематитом, гетитом, карнеол-агатом, аметистом, горным хрусталем, баритом, кальцитом. Наблюдаются срастания в виде почек гематита и гетита (рис. 3 а) и их срастания с карнеолом (рис. 3 б). В коричневооранжевых карнеол-агатах (рис. 3 в) отдельные зоны выделяются разным соотношением включений гидрооксидов железа (до 3-7.5 \%) с примесью $\mathrm{Al}$ (0.2-0.38 \%). В рудных образцах встречается кварц и карнеол с вростками гетита.

Район дер. Кондобережская в Онежской палеопротерозойской структуре с 80-х годов прошлого века известен проявлением пестроцветных яшм и карнеол-агатов, разведанных ПО «Северкварцсамоцветы» (Гутцайт, 1987). Уникальные (древнейшие в России) карнеол-агаты представлены концентрически зональными оранжево-красными обособлениями размером до $30 \mathrm{~cm}$. Внутренние полости секреций обычно зарастают аметистом и кварцем различной окраски (рис. 4).

$\mathrm{B}$ зоне окисления были обнаружены вторичные минералы: самородный селен $\mathrm{Se}$, сера $\mathrm{S}$, минералы ряда коркита-кинтореита $\mathrm{PbFe}_{3}\left(\mathrm{PO}_{4}\right)\left(\mathrm{SO}_{4}\right)(\mathrm{OH})_{6}-\mathrm{PbFe}_{3}\left(\mathrm{PO}_{4}\right)_{2}(\mathrm{OH})_{6}$, установлен ярозит $\left.\mathrm{KFe}_{3}\left(\mathrm{SO}_{4}\right)_{2} \mathrm{OH}\right)_{6}$, пластичатый ковеллин. Минерал селен практически на $100 \%$ состоит из одного элемента. Он всегда развивается по клаусталиту. Самородная сера по трещинкам выделяется в сфалерите (рис. 2 е). Галенит обычно замещается англезитом, но среди вторичных минералов встречаются белые прожилки редкого фосфато-сульфата - коркита (Р 3.21-3.88 \%, S 6.05-6.90 \%, $\mathrm{Fe} 23.11-27.13$ \%, Pb 25.05-26.65 \%, O 22.0-24.06 \%) (рис. 3 д) Весьма необычным является ярозита в срfствнии с тонкодисперсным кварцем (рис. 3 е), его состав: Fe 7,15\%, S 20,07 \%, K 11,34 \%, Fe $17.02 \%$, О $37.24 \%$.

\section{Заключение}

Кварцевые жилы содержат ассоциацию сульфидов и селенидов. При смене обстановки минералообразования ассоциация сульфидов замещается сменяется оксидами - гематитом, гетитом, тонкодисперсными разновидностями кварца (карнеол-агатом) и затем на более поздней стадии полости опять зарастают кварцем. В окисленном типе руд при частичном замещении пирита гематитом и гетитом клаусталит частично сохраняется и затем замещается самородным селеном. При гипергенном изменении сфалеритовых агрегатов образуется сера. При изменении полисульфидных агрегатов образуются ярозит и коркит. Типоморфными элементами рудной минерализации являются $\mathrm{Fe}$, $\mathrm{Zn}, \mathrm{Cu}, \mathrm{Co}, \mathrm{S}, \mathrm{Se}, \mathrm{Ba}, \mathrm{P}$.

Проведенные авторами исследования в районе пос. Великой Губы предполагают более позднее образование карнеолов в близповерхностных условиях, при повышенных концентрациях гидроксидов железа. Впервые для Карелии были обнаружены в зоне окисления самородный селен и сера, а также другие гидросульфато-фосфатные минералы.

\section{Литература}

1. Гутцайт Г.Я. Отчет о результатах поисковых работ, проведенных в Карельской АССР на участке Кондобережском в 1985-87 г.г. Северное производственное объединение «Северкварцсамоцветы». Л. 1987.

2. Минерально-сырьевая база Республики Карелия. 2006. С. 278.

3. Онежская палеопротерозойская структура (геология, тектоника, глубинное строение и минерагения) (Отв. ред. Глушанин Л.В., Шаров Н.В., Щипцов В.В.). Петрозаводск. 2011. 431 с. 